\title{
SEXUAL HARASSMENT IN MALAYSIAN EDUCATIONAL INSTITUTIONS: CAUSES AND SOLUTIONS ${ }^{*}$
}

\author{
Ashgar Ali Ali Mohamed', Farheen Baig Sardar Baig ${ }^{2}$, Adnan Trakic ${ }^{3}$, \\ Muzaffar Syah Mallow ${ }^{4}$, Ahmad Tijani Surajudeen ${ }^{5}$
}

\author{
${ }^{1}$ Prof. Dr., Ahmad Ibrahim Kuliyyah of Law, International Islamic University Malaysia (IIUM)*, \\ ashgar007@yahoo.com.sg \\ ${ }^{2}$ Associate Prof. Dr., Ahmad Ibrahim Kuliyyah of Law, International Islamic University Malaysia \\ (IIUM), baigfarheen007@yahoo.com \\ ${ }^{3}$ Assistant Prof. Dr., Monash University Sunway Campus, Malaysia trakic.adnan@gmail.com \\ ${ }^{4}$ Assistant Prof. Dr., University Saint Islam Malaysia (USIM), muzaffarsyah@yahoo.com \\ ${ }^{5}$ PhD Candidate, Institute of Education, International Islamic University Malaysia (IIUM), \\ sirajudeen 20@yahoo.com \\ ${ }^{*}$ Corresponding author
}

\begin{abstract}
The vitality of school in proffering solutions to the societal challenges cannot be underrated. However, school as a hub and pivot place in addressing multifarious challenges in our society is faced with some social ills such as bullying and sexual harassment. More profusely, an escalation of sexual harassment in schools' and on campuses cannot be denied. More copiously, of greater challenges in our contemporary period is inadequate and ineffective measure to curb prevalence of sexual harassment. More so, there are few existing guidelines in combating sexual harassment such as the Penal Code, Employment Act and the Code of Conduct for Industrial Harmony. However, there is yet to be a proper academic focus providing a deep investigation and crystal clear explanation in drastically minimizing or eradicating the prevalence of sexual harassment in schools and higher institutions of learning by formulating a policy and procedure in eschewing sexual harassment in schools in particular and society in general in the country. Hence, this paper elaborately explicates the various issues relating to sexual harassment in the Malaysian schools and higher institutions of learning and further, the various approaches towards its prevention.
\end{abstract}

Keywords: Sexual Harassment, Educational Institution, Causes and Solutions

\section{INTRODUCTION}

Malaysia has continuously played a significant role in all spheres of human endeavours such as economy, political, social, education, technology and banking, among others, in the Asia in general and South-East Asia in particular. Like many other countries, developed and developing alike, the country is not spared from various social problems such as baby dumping, assassinations, wrongful killings, injuries, bullying and sexual harassment, among others which undoubtedly, are common scenario or phenomenon today in the public domains. School as a hub and pivot place in addressing multifarious challenges in our society is also faced with some social ills specifically bullying and sexual harassment. It must be pointed out that outraging modesty of another or using obscene language, suggestive remarks and unwanted physical contact, among others, is improper, unbecoming and unacceptable standards of behaviour expected in any civilised society.

Harassment consists of offensive, abusive, belittling, humiliating, threatening or intimidating behaviour directed at a person or a group of persons. Sexual harassment refers to sexual conduct which is imposed

\footnotetext{
* This paper is prepared for presentation at the SOCIO-INT14 - International Conference on Social Sciences and Humanities to be held in Istanbul, Turkey on the 8th, 9th and 10th of September, 2014
} 
on, and is unsolicited or unreciprocated by the recipient. Examples would be repeated unwelcome sexual comments, looks or physical contact, among others, which are usually committed by male against female or vice versa. Sexual harassment may occur in many places such as in the workplace, schools, or other public places. In schools, sexual harassment may be committed either against the teachers or administrators of the institution or against peers or colleagues. For it to constitute sexual harassment the conduct of the accused must be unwanted or unwelcomed. The recipient much perceived the conduct as placing a condition of a sexual nature and further, it must be offensive or humiliating or a threat to his/her well-being.

Against the above backdrop, this paper is aimed at addressing the causes of sexual harassment in the secondary schools and institutions of higher learning and further, proposes viable solutions for its prevention in the Malaysian contest. It is argued that the students must know when they are being sexually harassed either by their peers, teachers or others, during or after school hours and probably even in their own homes. It is noteworthy that sexual harassment offence are often committed in the classroom or other areas within the school premise, as well as on the way to and from school, which is basically outside the control of the school authority. Further, reference is also made to mode of handling such cases with reference to the approaches taken by selective institutions of higher learning in Malaysia.

\section{SEXUAL HARASSMENT REPORTED WITHIN AN ACADEMIC SETTING}

More profusely, an escalation of sexual harassment in schools and on campuses cannot be denied. The range of sexual harassment reported within an academic setting is alarming. The examples of the sexual harassment conducts includes, sexual comments, jokes, gestures or looks; touching, grabbing or pinching in a sexual way; making sexual rumours spread about another; intentionally brushing up against another in a sexual way; blocking another in a sexual way; showing, giving or leaving sexual pictures, photographs, illustrations, messages or notes; the clothing of the victim pulled off or down in a sexual way; forcing the victim to kiss someone; had sexual messages written about another on public walls; forced to do something sexual other than kissing; spied on while dressing or showering, to mentioned but a few. Further, more girls are reported to have experienced sexual harassment as compared to boys and it does impact their school performance, such as a difficulty of concentrating in their studies, fear and lower self-esteem, among others.

Sexual harassment is not merely a contemporary silent issue in the Malaysian academic institutions but is a worldwide problem. Previous studies showed that the sexual harassment in academic settings is prevalent in many countries such as in the United States, Netherlands, Germany, Canada, Taiwan, Pakistan, Philippines, Turkey and Ecuador, to name but a few (Sigal, J. et. al, 2005). As noted earlier, there are different categories of sexual harassment in the schools and universities. It can emanate from lecturer/teacher to student; student to lecturer/teacher; and student-to-student. The student-to-student sexual harassment is common and prevalent in secondary schools and tertiary institutions. This may take different forms such as verbal, physical and non-verbal. Verbal harassment entails any upsetting or insulting words directed at someone because of her/his sex. For example, certain nicknames like 'stud,' 'babe,' 'chick', or 'sexy' may have some connotations. Physical harassment is any unwanted physical contact. This may include (but is not limited to) touching, grabbing or pinching in a sexual way. This may be regarded as sexual assault which is a criminal offence. Non-verbal (without words) harassment may include leering (staring), or sexual gesturing (movements) (Sigal, J. et. al, 2005).

Despite advocacy of non-discrimination between female and male in education, sexual harassment in schools and higher educational institutions has drastically prevalent. There are few existing guidelines in combating sexual harassment such as the criminal law. The Penal Code makes provisions for the offences of assault (section 351), outraging of modesty (section 354), rape (section 376), outraging of decency (section 377-D), criminal intimidation (section 503) and using words or gestures to insult the modesty of a woman (section 509). Specifically, section 509 states: "Whoever intending to insult the modesty of any woman, utters any words, makes any sound or gesture or exhibit any object, intending that such word or sound shall be heard, or such gesture or object shall be seen by such woman, shall be punished with imprisonment for a term which may extend to 5 years or with fine or with both". Despite postulation for the severe punishment for sexual assault in the Penal Code, the recent research finding have shown that there is high rate of the students' experience of sexual harassment in various schools and institutions of higher learning in Malaysia which have a tendency of causing long term psychological disturbances to the victims (Ng, C., Jamilah Othman, 2002). The survey of sexual in the context of Malaysian schools and institutions of higher education is briefly discussed below. 


\subsection{Sexual Harassment Survey in Schools}

The survey of sexual harassment herein was with reference to secondary schools in the country mainly because at this age, teens are not only concerned about a heavier class load, but they also worry about social issues such as fitting in, having friends, being judged or their appearance. In addition to these concerns there are other problems associated with secondary school that can interfere with grades or cause physical and psychological problems. Bully-victim problems, sexual harassment as well as racial discrimination are major concern among the students in the Malaysian secondary schools.

As part of the safety in schools, several private secondary schools which implement similar educational program system with the public secondary schools in Kuala Lumpur as well as in several states have been selected for this research survey in order to understand the extent of sexual harassment occurrence in the schools. Due to sensitivities of the research, the name of the secondary schools had to be withheld. For this research survey, two set of target audience had been approached namely, the secondary school students themselves as well as the teachers and the administrative staff of the schools. The survey is based on the responses from selected 50 teachers and administrative staff members as well as over 200 respondents among students from these selected secondary schools. The analysis of the survey data had to be omitted because of the restricted page limits imposed by the organisers of this conference.

From the survey result it was noted that a handful of teachers / administrative staff were aware of the seriousness of the issue and took proactive steps to deal with the problem in their respective schools. Significant numbers of students i.e., more than $50 \%$, experienced harassment and they reported trouble sleeping, staying away from school and stopping school activities or sports. Some students even found it necessary to switch schools. As the young people's stories make clear, sexual harassment is a reality for both girls and boys, although girls are more vulnerable to sexual harassment.

\subsection{Sexual Harassment in Institutions of Higher Learning}

Sexual harassment is also a common problem among university students. Eighteen (18) students as participants from selected local universities pursuing masters and $\mathrm{PhD}$ courses were selected. The interview sessions covered general questions regarding sexual harassment in Malaysian universities. Based on the discourse unit (D.U.), themes were generated. On the whole, the interview finding indicates that the students in the university were familiar with the term 'sexual harassment' and are aware of its incidence in the Malaysian context (D.U.1). Majority of interviewees agreed that sexual harassment is increasing among Malaysian public and private universities (D.U.2).

The assumption of the respondents is that the initiatives to prevent sexual harassment are still scarce, which may be the reason for the frequent occurrence. Further, many of the participants or interviewees felt that the victims are most commonly female students as they are more vulnerable to sexual harassment (D.U.3), while others stated that both male and female are victims (D.U.4). Some respondents believe that the Malaysian education system's emphasis on a western syllabus and low priority given to religious subjects, resulting in exposure to certain elements in the education system that may influence this issue (D.U.5). However, another viewpoint is that it is not the education system that causes this problem, but it is believed that the environment and society are the biggest reasons for sexual harassment (D.U.6).

In addition, majority of the respondents felt that students' invite sexual harassment on themselves by their improper dressing. This is cited as one of the biggest factors. The emphasis on proper dress-code by university management is one of the ways in which this can be solved and this is being done by many universities. Further, majority of the respondents also agreed that close proximity must be illegalized in higher learning institutions. The reason is that close proximity is one of the major factors that can lead to negative manner and social effects occurring especially among students. Thus, students should abide by the rules prescribed by the universities and appropriate punishment should be imposed on the defaulters of the university regulations.

\subsection{Sexual harassment from employment law}

In the context of employment law, sexual harassment is categorised as a major misconduct that could warrant dismissal from employment, if established on a balance of probabilities. Generally, employees of the public and private educational institutions, specifically the teachers and the administrative staff members of the school, are governed by the 'Guidelines for Handling Sexual Harassment in the Workplace Among the Civil Servant No. 22 of 2005' and the 'Code of Practice on the Prevention and Eradication of Sexual Harassment in the Workplace', respectively. Besides defining 'sexual harassment' and mode of handling 
such offences, the above instruments serve as preventive measures against incidents of sexual harassment. Further, the Employment Act 1955 part XVA contains procedures in dealing with complaints of sexual harassments. Section 81F of the said Act makes it obligatory on the employer to attend to their employee's complaint of sexual harassment committed either by a co-worker or by the client / customer of the employer. Failure to act promptly on the complaint, the employer may be liable to fine of up to ten thousand ringgit, if found guilty.

\section{DESTRUCTIVE EFFECTS OF SEXUAL HARASSMENT ON VICTIMS}

The destructive effects of sexual harassment on victims are briefly noted herein although the same is not the primary aim of this paper. Previous studies have indicated that female students are more vulnerable to sexual harassment and they tend to experience sexual harassment during their college days which inferably will hitherto affect their academic performance (Cortina, \& Wasti, 2005). Most of sexual harassment experiences by females are caused by male harassers (Berdahl, Magley, \& Waldo, 1996). The literature shows that sexual harassment is so destructive to the psychological, physical and emotional well-being of the victims. In fact, a number of theoretical and empirical studies have demonstrated that sexual harassment has a tendency of causing long term psychological disturbances to the victims (Berdahl, Magley, \& Waldo, 1996). Several studies have painstakingly examined the psychological impact of sexual harassment on the victims (American Association of University Women 2006).

Incidents of sexual harassment also contribute immensely to the low self-confidence, self-esteem and more detrimentally, it affects the psychological well-being of the victims (Pryor, John and Louise Fitzgerald, 2003). Self-esteem is crucial for students and is connected with anxiety (American Association of University Women Educational Foundation, 1995). Those with low self-esteem picture themselves as worthless and unpleasant. Symptoms of anxiety may be nausea, headaches, muscular spasms, insomnia and high blood pressure (American Association of University Women Educational Foundation, 1995). In a situation where sexual harassment persists, it may lead to severe stress and associated diseases on a student (American Association of University Women Educational Foundation, 1995). Significant numbers of students who experienced harassment reported sleeplessness, staying home from school and stopping activities or sports. Some students even found it necessary to switch schools.

The most irreplaceable implication of sexual harassment which psychologically affects the harassed person is health. The Post-Traumatic Stress Disorder (PTSD) is commonly associated with the victims of sexual harassment or sexual victimization or assault. The individual responses to the sexual harassment will be depended on the circumstances or scenario through which the harassment occurred (Frazier, (2000). For instance, female students who are sexually harassed or raped undeniably can result to pregnancy, which will certainly affect the academic performance of the victim besides affecting her health. The students will also be exposed to sexually transmitted infections (STDs). It has been reported that many female students that have been raped or sexually abused have been contracted with STDs (Frazier, 1990). Further a physical attempt of the victim to resist the harassment could lead to physical injury (Osman, Suzanne, 2004).

Depression as an abnormal feeling is ascribed psychological disturbance to the victims of sexual harassment. Although, there are many other psychological and emotional feelings experienced by the harassed person, however the reality is that depression is among the most vital of them. The findings have shown that, the sexually harassed victims who are depressed usually thinking of committing suicide hence, it requires legal and medical approaches (Campbell, 2005). The case of suicidal thoughts is taken seriously in many developed countries because the psychological impact of sexual assault on the victims is a serious matter. For instance, there is National Suicide Prevention Lifeline (NSPL) in the United State of America (USA) whose primary responsibility is catering for those who were affected by depression that can lead to suicidal thoughts (National Center on Domestic and Sexual Violence, 2006). This is the reason why, the suicide experts have submitted that, the depressed person should be talked to or advised and the same applies to those contemplating suicide.

Both the psychosomatic and physical effect of sexual harassment can result in low academic performance and grades. This is particularly so because the students are psychologically and emotionally imbalanced, therefore they will not be able to focus on their studies, henceforth; their academic performance will be affected. For instance, the victim may elect to abandon a class due to fear of intimidation or they may restrict their involvement in classroom deliberations (National Center on Domestic and Sexual Violence, 2006). Hence, it is importantly paramount that sexual harassment which affects both the academic performance as well as the health of the victim students either in secondary or university level in the context of Malaysia should be taken seriously. The above has been corroborated in the study of Straight et al. (2003) that female students in the college who are sexually harassed tends to be psychologically affected especially in terms of 
their health and their social behaviour or interaction. The impacts mentioned by the harassed female students include: lack of proper concentration in study, fear, and low self-esteem, among others (Gutek, \& Koss, 1993).

Inferably, it could be said that, female students whose health and social interaction are affected as a result of sexual abuse will be de-motivated to perform excellently in their academic activities. The hypothesis has explicitly demonstrated the predictors of sexual harassment which hitherto affects the students' academic performance (Huerta et al., 2006). It has been seen vividly that it contributes to the level of students' academic dissatisfaction which also leads to psychological stress and physical illness of the students (Huerta et al., 2006). It has been further reiterated that the low level of students' academic satisfaction and psychological distress contribute to physical illness, disordered eating which leads to their academic disengagement as well as physical illness. Hence, the academic disengagement of the students contributes to the woeful academic performance (Huerta et al., 2006).

\section{SEXUAL HARASSMENT: THE CAUSES}

Various empirical and theoretical studies have tried to proffer solutions and coping mechanisms to the challenges of sexual harassment. More copiously, of greater challenges in our contemporary period is inadequate and ineffective measure to curb prevalence of sexual harassment in the educational institutions in the Malaysian context. As noted earlier, sexual harassment can happen anywhere within and outside schools, in the classroom, the locker room, on a field trip, sporting event, and even outside school premise such as on the way to and from school. However, sexual harassment is likely to happen when there is no clear observation from the school authorities for example, during class breaks, lunch or recess, among others.

Further, with the prevalence of sexual harassment in Malaysian educational institutions, authorities have not taken proactive measures to create awareness among its students about the issue. This probably could be because of the sensitivity of the issue amongst the Asian society which considered discussion on sexual acts including sexual harassment a taboo matter. With that reasons, it is hard for the students to learn what constitutes sexual harassment and more important what they need to do when they encounter with such incidents. Having said the above, based on the research conducted in the selected secondary schools and the institutes of higher education in Malaysia, the causes for the high occurrence of sexual harassment incidents in Malaysia is highlighted below.

\subsection{Indecent dressing}

While the perceptions of people with respect to indecent dressing might be different, generally the indecent dressing that reveal their privacy might influence the opposite sex in the school environment to initiate social interaction that might subsequently lead to sexual harassment (Muhammad Nazari Ismail, Lee KumChee and Chan Foong Bee, 2007). Wearing skimpy or transparent wears for example, may arouse the sexual emotional attachment that could lead to physical, verbal and non-verbal sexual harassment. Studies have shown that campus girls who are dressed skimpily and revealing dresses was associated with the expectations of compliments, wishes and demands to be gratified (Chukwudi \& Gbakorun, 2011).

\subsection{Exposure to sexual materials}

Students are enticed by sexual materials that are accessible to any internet browser and this arouses their sexual emotions which then lead to sexual harassment. One of the vulnerabilities of information communication technology is the introduction of e-sexual harassment with the use of electronic networks for sending pornographic pictures, sexual messages and many other illicit sexual activities (Richard, 1993). Recent study shows that sexual jokes among employees could create a hostile work environment (Ashgar Ali Ali Mohamed, Muzaffar Syah Mallow and Farheen Baig Sardar Baig, 2012). Inferably, sexual jokes are also common among the students which undoubtedly have a tendency of creating hostility by female students towards male students as they may perceive it as a form of harassment.

\subsection{Use of illicit drugs}

Studies have shown that the use of illicit drugs has a tendency of making one to commit sexual misconduct besides negative effects illicit drugs on the personality of students (Katz, Fromme, 'Amico, 2000). Further, the prevalence of the use of alcohol among secondary school and college students has contributed to sexual harassment (Dermen and Cooper (1994). However, it has been noted that there is no consistent findings regarding the use of alcohol as a factor leading to sexual harassment (Jennifer Brown, and Peter). 
Interestingly, in the context of Malaysia, in the 1980s, the Ministry of Education had advocated for proactive action against the youngsters or youth involved in drugs and alcohol in schools (Amir, \& Latiff, 1984). The efforts were made at preventing sexual harassment involving the students in the country. Nonetheless, with the current scenario of the prevalence of sexual harassment among the youngsters is that there has been deterioration with respect to efforts in combating the use of illicit drugs among the youngsters.

\subsection{Secluded areas in sexual harassment}

It is on record that in the context of school or college environments, a particular situation that the harasser and the victim find themselves tends to contribute to the sexual harassment (Adams-Curtis, Forbes, 2004). For instance, male and female students that find themselves in a secluded area have a tendency of being subjected to sexual harassment compared to those who are engaging in their academic activities in an open place.

\section{ELIMINATION OF SEXUAL HARASSMENT: SOLUTIONS AND RECOMMENDATIONS}

Regardless of whether the victim files a formal complaint or requests action, the school must conduct a prompt, impartial, and thorough investigation to determine what happened and must take appropriate steps to resolve the situation. If other sources, such as a witness to the incident, an anonymous letter or phone call, or the media report on the harassment, the school should respond in the same manner described above if it is reasonable for the school to conduct an investigation and the school can confirm the allegation(s). Considerations relevant to this determination may include, but are not limited to, the source and nature of the information; seriousness of the alleged incident; specificity of the information; objectivity and credibility of the source that made the report; ability to identify the alleged victims; and cooperation from the alleged victims in pursuing the matter (Dziech, Billie Wright, Weiner and Linda, 1990).

The appropriate steps should be tailored to the specific situation. For example, the school may need to develop and publicize new policies or conduct training. Depending on the nature and severity of the harassment, counselling, discipline, or further separation of the victim and harasser may be necessary. Responsive measures should be designed to minimize the burden on the victim as much as possible. If the school's initial response does not stop the harassment and prevent it from happening again, the school may need to take additional, stronger and effective measures.

Sexual harassment can be eliminated if schools and universities have clear and effective policy in place for the purpose of its prevention and cure (Fitzgerald, \& Shullman, (1993). The sexual harassment policy need to be implemented by making sure that every student, parent, and school employee should receive a copy of the policy and complaint procedures or a brochure or pamphlet summarizing it, as well as regular reminders about it. Also a description or summary of the policy, with names of persons to contact for more information, should be included in all major school publications such as handbooks, course catalogues, or orientation materials. No matter how comprehensive the policy is on paper, it will be ineffectual unless it is enforced.

The young should be educated to understand and act against sexual harassment. This is done through training the students in the secondary schools and in institutions of higher learning. The participants should be made to answer questions such as the forms of sexual harassment; the prospective victim and the perpetrator; and possible action taken by the victim, among others. The aim is to create awareness among students about the issue of sexual harassment.

The Parent-Teacher-Association (PTA) and concerned adults can play pivotal roles in creating a healthy school and community climate that is free of sexual harassment. By working together, educators, parents, concerned citizens, business leaders, advocates, and community leaders can support the implementation of bullying prevention programs, reinforce bullying prevention messages, and advocate for bullying policies to be implemented. This collaboration is critical as bullying happens everywhere that young people gather, including online, via text, and in social networks. PTA leaders and parents can play an important role in convening community conversations to build awareness of this as an important issue and to take action to stop any event of sexual harassment or violence within communities. A founding purpose of PTA is to promote safety for children and youth.

Religious doctrine, faith, creed and morality are effective to eradicate antisocial and immoral behaviours. It could be argued that sexual harassment is one of anti-social behaviours that religious moral values could address. From a religious perspective, all forms of sexual harassments are considered sins to man and God and contribute towards the destruction of society. It has been vividly explained that spiritual and moral 
standards of religions are essential in dealing with all forms of sexual harassment especially among students in Malaysian schools. Therefore, since religion deal with faith and morality, and people have been preoccupied with material wealth, little attention is given to faith and moral standards within the society. As a result of the focus on worldly materials, many immoral acts are common in the society.

Many knitted ideas and thoughts regarding sexual norms are discussed from a religious perspective. The scholars' ijtihad in prohibiting male and female social interaction that can lead to illegal sexual affairs is based on the precepts of "blocking the means to sin" popularly known as "Sadd al-Dhari'ah". Another precept explains that whatever that can lead to the unlawful is also unlawful. Therefore, it can be inferred that phone calls to the opposite sex with sexual desire can lead to sexual assault or harassment; accordingly such acts are also unlawful. Therefore, these Islamic precepts and moral values can be formulated into procedures, policies and guidelines in combating sexual harassment among students in schools and institutions of learning in Malaysia. As a result, the inculcation of religious moral values among the students will be helpful in restricting the social interaction between male and female students in schools and institutions of higher learning in the country.

\section{POLICY AND PROCEDURE ON SEXUAL HARASSMENT IN UNIVERSITIES}

Although many schools and universities in Malaysia generally do not have a specific policy and procedure on sexual harassment, in many universities in the country however, sexual harassment would constitute a breach of the internal University Disciplinary Rules, and as such, it would be sanctioned. The above is discussed below with reference to the International Islamic University Malaysia and University Malaya.

\subsection{International Islamic University Malaysia}

The International Islamic University Malaysia (IIUM) Student's Discipline Rules 2004 contain provision on sexual misconduct. For example, rule 30 provides: "No person not being a mahram shall within or outside the University, engage in any kind of sexual conduct with any member of the University or visitor to the University which may also include other serious or persistent unwanted sexual contact or conduct, such as harassment, threats, intimidation or unwanted touching or fondling." Similar provision involving employees of IIUM is found in the Staff Disciplinary Rules 2005 (Amendment 2012). Cases involving sexual misconduct among students will be tried by the Domestic Inquiry (tribunal) which will hear the charge and make its recommendation to the Student Disciplinary Committee which will then decide whether to accept, vary, or decline the recommendation made by the panel of the Domestic Inquiry (D.I.). Aside from the above, although IIUM has not adopted any specific policy on sexual harassment in campus, nevertheless there are certain codes of conduct in place which can serve as measures to control incidents of sexual harassment in the said institution. These measures are as follows:

\subsubsection{Dress Code}

The University has prescribed a dress code standard for female and male students. The sample of this dress code is pasted or placed in strategic places on the campus. As noted earlier, one of the causes of sexual harassment is physical attraction. It is therefore necessary for the University authority to put in place a mechanism for guiding student's dress code. Vigorous enforcement of the dress code is necessary to ensure that incidents of sexual harassment do not occur.

\subsubsection{Sitting arrangement}

It is common practice in IIUM to separate the sitting arrangement of gender both within and outside classrooms. It is customary in the classroom, conferences, and training programme to divide the sitting arrangement of both sexes. This sitting arrangement would be able to minimise incidents of sexual harassment besides encourage concentration and attention in classroom.

\subsubsection{Minimization of privacy}

An environment or school setting characterised with so much privacy offers a better prospect for harassment because it may be difficult to observe and notice unwanted advances. Thus, it has been projected that an environment with extremely private settings is more likely to encounter harassment than those with more open environments. There is a dichotomy between privacy and making the work environment open. Everyone has the right to his or her privacy without interference. However, the university environment is made open for students and staff to view without necessarily interfering with a person's privacy. For instance, offices and public places in IIUM are built or constructed with translucent glasses easily viewable 
from outside. This may serve as a check on an erring staff member or student and prevent unnecessary abuse. Also, it is customary to see security personnel especially at night patrolling the campus. In a situation where discrete mixing is taking place, the involved persons may be separated or other measures may be taken depending on the nature of seclusion and what they are doing at that moment.

\subsubsection{Installation of closed circuit television (CCTV)}

This is another instrument put in place to curb unlawful activities, especially sexual harassment on campus. CCTV has a psychological effect on the attitude of the student. They are installed in strategic places on campus and capable of exposing ill act of students and staff. This has gone a long way to control indecent attitude on campus and checkmate the behavioural pattern of students and staff. Where this is truly functioning, act of sexual harassment can easily be noticed and appropriate measure can be subsequently taken against it.

\subsection{University of Malaya}

In an attempt to create a safe and healthy working environment for students and staff, the University of Malaya in 2008 issued a hand book titled Code of Practice on the Prevention and Handling of Sexual Harassment Cases in the University. The university has also established the Sexual Harassment Complaint Bureau to support UM community who need help in handling the sexual harassment issues. The power of the Bureau is to investigate and take appropriate measures against the harasser. The Code identified various forms of harassment such as verbal, non-verbal or physical kind. The Code proves that the UM commitment is committed in nurturing an environment that is free from sexual harassment. The Code has specified the procedures of complaints against sexual harassment within the campus which are highlighted below:

The complaint is to be made by completing the sexual harassment Form for lodging a complaint within legislative and common law framework of Malaysia such as sexual assault and molestation. Complaint not made through the prescribed form may still be attended to by the Sexual harassment Complaint Bureau so as to relieve the complainant of sexual harassment burden. The complainant will be advised by the Bureau as to the appropriate actions to be taken.

The Bureau will in the case of formal complaints, carry out investigations to obtain important information as follows: (i) clarification on sequence of events; (ii) parties involved; (iii) the time it happened; (iv) whether the offence was committed for the first time or a repeated offence; (v) whether any physical evidence available regarding the incident; (vi) witnesses, if any, that could corroborate the incident; and (vii) whether the incident has been reported to a third party. The tardiness to lodge a report/complaint or the lack of physical evidence of a struggle should be held against the complainant. The evidence gathered by the Bureau will determine the appropriate steps or measures to be taken.

The suspected offender will be given the right to make his defence. That is, he or she will be given the opportunity to explain and clarify the sequence of events. The essence of this is to ensure a fair trial. There are a few possibilities of findings by Bureau which may include: dismissing the complaint as being baseless; a solution without official action taken against the offender and with the agreement of the complainant; or a finding that the complaint is viable or has really occurred.

Where the complaint was established, disciplinary action will be taken against the harasser as follows: (i) where the harasser is a staff member of the university, such a person may be reprimanded, fined, salary movement withheld, demotion, or dismissed from employment; (ii) where the harasser is a student, such student may be warned, fined, prohibited from entering any part of UM campus, suspended from studies in UM, or expelled from UM; and (iii) where the harasser is an outsider, the person may be prohibited from dealing with UM community members or prohibited from entering any part of UM campus. Where the allegation of sexual harassment is found to be baseless, suitable compensation may be considered for the person wrongfully accused.

It needs to be mentioned that apart from the procedures set out in the Code to address incidents of sexual harassment in the campus, the University has introduced a Special Committee on Sexual Harassment. The sole task of the Committee is to create awareness on the campus as to the evil effects of sexual harassment and educate the students of their rights in the event it does occur. The Committee is required to train suitable students and staff of the University with counselling skills to assist those who have become victims of sexual harassment. It is also expected of the Committee to publicise information regarding the existence of the Code of Practice for Prevention of Sexual Harassment in University Malaya. With the adoption of the policy on sexual harassment as above, the University has proven its seriousness in addressing this issue. This is a 
good and commendable step which should serve as an example to other institutions of higher learning to take similar pragmatic steps and measures towards the prevention of sexual harassment in their respective environment.

\section{CONCLUSION}

Sexual harassment incidents in the schools or institutions of higher learning are considered as social liability. The extent of seriousness of sexual harassment is reflected in its psychological impact on the victims' academic performance besides affecting their health and self-esteems. It is paramount that there must be cooperation among the relevant authorities, community and religious leaders and government officials in order to address the predicament and detrimental consequence of sexual harassment in schools and institutions of higher learning. It is the school's obligation to ensure that the harasser does not get a second chance to commit the same offence against the victim or others. Although, there are no legal requirements for the schools and universities in Malaysia to have a specific in-house policy and procedure in dealing with cases of sexual harassment, nevertheless, some have on their own initiatives, adopted certain policies and procedure. For example, the Sexual Harassment Complaint Bureau of the University of Malaya provides help to victims in handling sexual harassment incidents and this is a good initiative which may be emulated by other universities. This effort might create a safe and healthy working and learning environment. A formation of a policy and procedure on sexual harassment is in fact a very effective tool curbing incidents of sexual harassment. After all, it is the responsibility of the schools and universities to provide a safe and conducive learning environment for their students and staff, free from any form of sexual harassment. Otherwise a longreigned paradigm that schools and universities are safe places for youth to be would be undermined.

\section{ACKNOWLEDGEMENT}

The principal researcher, Prof. Dr. Ashgar Ali Ali Mohamed of Ahmad Ibrahim Kuliyyah of Law, IIUM acknowledges the financial support of this research by the Malaysian Ministry of Higher Education (MOHE). The Research Management Centre (RMC), IIUM is also acknowledged.

\section{REFERENCE LIST}

Adams-Curtis LE, Forbes GB. (2004). College women's experiences of sexual coercion: A review of cultural, perpetrator, victim, and situational variables. Trauma Violence \& Abuse.5, pp. 91-122.

American Association of University Women Educational Foundation, Hostile Hallways, The AAUW Survey on Sexual Harassment in America's Schools, 1993 at 5; Kathryn Scott, "Seventy Five Years Later Gender- Based Harassment in Schools" (1995) 59 Social Education 293 at 293.

American Association of University Women. (2006). Drawing the line: Sexual Harassment on Campus. Washington, DC.

Amir, A., \&Latiff, M. (1984). Guidance and counseling in Malaysian schools: A review and critique .In Third Asian workshop on child and adolescent development (Vol. 2, pp. 1- 18).Kuala Lumpur, Malaysia: Universiti Malaysia, Faculty of Education.

Ashgar Ali Ali Mohamed, MuzaffarSyah Mallow and Farheen Baig Sardar Baig (2012). Sexual Harassment at the Workplace in Malaysia, Selangor. The Malaysian Current Law Journal Sdn Bhd., pp. 80-101.

Berdahl, J. L., Magley, V. J., \& Waldo, C. R. (1996). The Sexual Harassment of Men? Exploring the Concept With Theory and Data. Psychology of Women Quarterly.20, 527-547.

Campbell, R. (2005).What really happened? A validation study of rape survivors' help-seeking experiences with the legal and medical systems. Violence and Victims, 20, 55-68.

Chukwudi, F.\& Gbakorun, A. A. (2011). "Indecent Dressing and Sexual Harassment Among Undergraduates of Nasarawa State University, Keffi" Vol 3, No. 2 Journal of Sociology, Psychology and Anthropology in Practice 25.

Cortina, L. M., \&Wasti, S. A. (2005). Profiles in Coping: Responses to Sexual Harassment across Persons, 
Organizations, and Cultures. Journal of Applied Psychology.90, 182-192.

Dermen KH, Cooper ML. (1994a). Sex-related alcohol expectancies among adolescents: I. Scale development. Psychology of Addictive Behaviors. 8, pp. 152-160.

Dziech, Billie Wright, Weiner, Linda. (1990). The Lecherous Professor: Sexual Harassment on Campus. Chicago Illinois: University of Illinois Press.

Equal Opportunity Policy and Discrimination and Sexual Harassment Procedure, Monash University Sunway Campus. Retrieved from http://www.monash.edu.my/executive-services/policy/businessrules/rules-for- discrimination-and-sexual-harassment-procedure.html. (December 27, 2012).

Fitzgerald, L. F, \&Shullman, S. L. (1993). "Sexual harassment: A research analysis and agenda for the 1990s" Journal of Vocational Education, 42, 5-27.

Frazier, P.A. (1990). Victim attributions and postrape trauma.Journal of Personality and Social Psychology.59, 298-304.

Frazier, P.A. (2000). The role of attributions and perceived control in recovery from rape. Journal of Personal and Interpersonal Loss, 5, pp. 203-225.

Gutek, B. A \& Koss, M. P. (1993). Changed woman and changed organization: Consequences of and coping with sexual harassment. Journal of Vocational Behaviour. 42, 28-48. http://dx.doi.org/10.1006/jvbe.1993.1003.

Huerta et al. (2006): Sex and Power in the academy: Modeling Sexual Harassment in the lives of College women, Society for personality and social psychology bulletin. 616-628.

International Islamic University Malaysia (2004). Student's Discipline Rules, section 30.

International Islamic University Malaysia (2005). Staff Disciplinary Rules (Amendment 2012). Retrieved from http://www.iium.edu.my/legalunit. (December 27, 2012).

Jennifer L. Brown, M.S. and Peter A. VanableAlcohol Use, Partner Type, and Risky Sexual Behavior among College Students: Findings from an Event-Level Study.

Katz EC, Fromme K, D'Amico EJ. (2000). Effects of outcome expectancies and personality on young adults' illicit drug use, heavy drinking, and risky sexual behavior. Cognitive Therapy and Research.24, pp. 1-22.

Lavanian Nathan Jothy (2010). Sexual Harassment as Discrimination. File:///C:/Users/MySystem/Documents/Malaysian\%20Law\%20Since\%201997.html.

Muhammad Nazari Ismail, Lee KumChee and Chan Foong Bee (2007). Factors influencing sexual harassment in Malaysian workplace, Asian Academy of Management Journal, Kuala Lumpur: Universiti Malaya, p. 5.

National Center on Domestic and Sexual Violence. (2006). Family Violence in Later Life: Power and Control Wheel. http://www.ncdsv.org/ images/SeniorCitizenPCWheelNOSHADING-NCDSV.pdf.

$\mathrm{Ng}, \mathrm{C}$., Jamilah Othman (2002). Unwanted and Unwelcome: Sexual Harassment in the Malaysian Workplace. Gender Technology and Development 6, 389-406.

Osman, Suzanne L. (2004). "Victim Resistance: Theory and Data on Understanding Perceptions of Sexual Harassment." Sex Roles 50:267-75.

Pryor, John B. and Louise F. Fitzgerald (2003). "Sexual Harassment Research in the United States." Pp. 79100 in Bullying and Emotional Abuse in the Workplace: International Perspectives in Research and Practice, edited by S. Einarsen, H. Hoel, D. Zapf, and C. L. Cooper. London: Taylor and Francis.

Richard S. Rosenberg (1993). Free speech, pornography, sexual harassment, and electronic networks The Information Society: An International Journal, Volume 9, Issue 4, pp. 285- 331.

Sigal, J. et. al (2005). Cross-Cultural Reactions to Academic Sexual Harassment: Effects of Individualist vs. Collectivist Culture and Gender of Participants. Sex Roles, 52 (3)202- 215.

Straight, E.S., et al. (2003).The Impact of Partner Psychological Abuse on Health Behaviors and Health Status in College Women. Journal of Interpersonal Violence. 18(9), 1035-1054. 